\title{
Miasis Intracerebral, Generalidades y limitantes en el tratamiento, reporte de caso
}

Mariottiz Acuña SM ${ }^{1}$, Cardona Castellanos DP', Corredor Quintero AB ${ }^{3}$

1 Estudiante de pregrado de medicina - XII semestre de la Fundación Universitaria Juan N. Corpas, Médica interna del Hospital Departamental Universitario del Quindio San Juan de Dios Armenia.

2 Estudiante de pregrado de medicina - XII semestre de la Universidad de Boyacá, Médica interna del Hospital Departamental Universitario del Quindio San Juan de Dios Armenia.

3 Neurólogo Clínico, Fundación Universitaria Ciencias de la Salud (F.U.C.S.), Hospital Departamental Universitario del Quindio San Juan de Dios, Armenia, Colombia.

Autor de correspondencia: Sandy-mariottiz@juanncorpas.edu.co

Como citar: Mariottiz SM, Cardona DP, Corredor, AB. Miasis intracerebral: generalidades y limitantes en el tratamiento, reporte de caso. Revista Cuarzo 2017: 23 (2) 26-34.

Recibido: 25 de julio de 2017 Aceptado: 10 de octubre de 2017 Publicado: 30 de diciembre de 2017

\section{Resumen}

La Miasis es un parasitismo de los tejidos vivos o necróticos y órganos de los seres humanos causados por larvas de díptero, dentro de la clasificación según su localización se describe la miasis cavitaria, la miasis cerebral se describe como una entidad excepcionalmente rara, en esta se puede presentar la invasión del tejido meníngeo y encefálico, posterior a la perforación de los huesos del cráneo. Presentamos el caso de un paciente atendido en servicio de urgencias del Hospital Departamental Universitario del Quindío San Juan de Dios de Armenia - Colombia, quien consultó por múltiples cuadros de cefalea y malestar general, encontrando ulceración excavada, mal oliente, con infestación por larvas y huevos en el cuero cabelludo de región parietal y occipital con pérdida de tejido, recibió inicialmente manejo médico, los cuales no se lograban finalizar, dado que en la mayoría de ocasiones el paciente solicitaba retiros voluntarios. Luego de varios reingresos hospitalarios y tratamientos incompletos, el paciente ingresa al servicio de urgencias con gran deterioro neurológico, empeoramiento en su estado clínico y posteriormente fallece.

Palabras clave: Miasis, cerebral, cavitaria, Dípteros, Parasitismo, Tratamiento

\begin{abstract}
Myiasis is an infection by parasites that invade living or necrotic tissues and organs, it is cause by the larvae of diptero. The classification according localization is divided in cavity myiasis in which it can invade the meninges and brain after the perforation into de skull this condition is extremely wear (1), like the case we are going to discuss a patient who came to the emergency room (ER) service of the Hospital Departametal Universitario del Quindío San Juan de Dios Armenia -Colombia, for multiple episodes of headache and general discomfort; in the ER was found a excavated ulceration, smelly, with larvade and eggs in the parietal and occipital region, with scalp involvement and loss of tissue, he received treatment but they could not finish because the patient sign voluntary retirement of the hospital. After several admissions to the hospital and unfinished treatments, the patient comes to the ER service with large neurological deterioration, worsening clinical condition and he finally pass away.

Cerebral myiasis is exceptionally rare, most of the reports comes from developing countries and in Colombia there is not reports in literature of this that's why the need arises of report this clinical case of myiasis and more specifically his affectation on the brain.
\end{abstract}

Keywords: Myiasis, Cerebral, Cavitary, Diptera, Parasitism, treatment 


\section{Introducción}

El término Miasis, sustantivo derivado del griego (mya), fue propuesto por primera vez por el entomólogo inglés Frederick William Hope en 1840 para definir la infestación o parasitismo de los tejidos vivos o necróticos y órganos de humanos y animales provocada por larvas de dípteros (1), en contraposición a las causadas por larvas de insectos en general, y definido poco más de un siglo después por Zumpt en 1965, la Miasis es conocida como la infestación del hombre vivo con larvas de dípteros que se nutren de los tejidos del huésped (vivos o muertos) $(2,3)$.

El ciclo total del parásito dura de 3 a 8 semanas; es más corto en verano. El parásito pasa por diferentes etapas, dentro de las que describen la de huevo, larva, pupa y adulto $(2,4)$.

Existen diferentes tipos de clasificaciones dependiendo del grado de parasitismo, el tipo de alimentación, el tejido afectado y su localización $(2,4,5)$. Dentro de las más utilizadas para la práctica clínica encontramos la clasificación según su localización: (3).

1. Cavitarias: cuando el ataque de larvas tiene lugar, preferentemente, en la extremidad cefálica (senos paranasales y conducto auditivo externo). Las larvas destruyen cartílagos y huesos, ocasionando procesos mutilantes y complicaciones serias, e incluso mortales, de acuerdo con la región afectada. A la perforación de los huesos del cráneo puede seguir la invasión del tejido meníngeo y encefálico, causando meningoencefalitis y hemorragias. (3).

2. Cutáneas: Este tipo de miasis se presenta en tres formas clínicas:

- Forma forunculoide; Se presentan en la piel lesiones con franco aspecto forunculoso que contiene la larva en su interior, saliendo está en dos o tres semanas al exterior.

- Forma lineal rampante; La larva al migrar bajo la piel va creando dermografismo.

- Forma subcutánea; con tumores ambulatorios. Se forman tumefacciones profundas y dolorosas que a los pocos días se atenúan y desaparecen. Este proceso se repite en 10 semanas hasta que la última tumoración se ulcera dejando salir la larva (3).

3. Intestinal: En este caso las larvas son capaces de sobrevivir una vez ingeridas, desarrollarse e incluso multiplicarse en el tracto digestivo del hombre, señalando la posibilidad de reproducción de algunas larvas de insectos, sin necesidad de completar su ciclo, conocida con el nombre de pedogénesis (3).

Dentro de los principales factores de riesgo se han descrito: La exposición de úlceras, infecciones bacterianas de heridas o cavidades naturales (3), ingesta de alimentos contaminados, el hábito de dormir a la intemperie (indigencia) y pacientes con funciones físicas o mentales disminuidas (6), hospitalizados en nosocomios, carencia de condiciones higiénicas adecuadas, la diabetes, el estado inmunocomprometido (7) y el retraso en la búsqueda de atención médica agravan este problema $(3,4,6)$.
Un diagnóstico oportuno resulta importante no sólo para aliviar los síntomas del paciente sino también para prevenir el establecimiento de moscas causantes de miasis en regiones donde no son endémicas (1). La estrategia de prevención constituye una de las herramientas más significativas frente a esta patología, factores modificables como higiene personal, cuidado de heridas, control de la población de dípteros y el mantenimiento de medidas sanitarias a personas procedentes de áreas rurales y grupos socioeconómicos bajos quienes tienen un mayor riesgo (6), es precisamente en estas variables donde se debería intervenir.

Para el tratamiento se deben tener en cuenta diferentes aspectos como: El tipo de miasis, su localización, el estado general del paciente, incluyendo, estado de las lesiones, tiempo de evolución, e infecciones asociadas a dicha infestación $(2,8)$, dependiendo de ello se puede iniciar manejo mediante extracción manual de larvas, o bloqueo del aporte de oxígeno a dichas larvas con sustancias como el cloroformo, éter o creolina (8). Se ha descrito la utilización de diferentes métodos como el aceite, parafina, petróleo, cintas, yesos, esmalte de uñas o cera de abejas entre otros para estimular la salida de estas larvas (2).

Otros mecanismos para el desbridamiento de tejidos comprometidos, son la extracción quirúrgica de larvas bajo microscopia por el riesgo de dejar una larva o parte de ella dentro de la lesión y posteriormente pueda convertirse en infección o granuloma (2). Como tratamiento farmacológico efectivo encontramos la ivermectina con gran poder insecticida y vermicida única utilizada en humanos, se puede usar de forma segura, es económica y de fácil administración, combinado también con ungüentos de aversectina se han encontrado resultados importantes en su uso sistémico (8), así como también se han visto excelentes resultados con el uso de agentes antibacterianos - antiparasitarios principalmente usados contra infecciones por agentes anaerobios tales como el metronidazol. Es importante el conocimiento de esta patología, a fin de poder identificarla rápidamente e instaurar el tratamiento necesario, ya que generalmente es un cuadro autolimitado y cura sin dejar secuelas importantes (5).

Los sitios anatómicos más comúnmente afectados por la miasis son ojos, heridas cutáneas, senos paranasales, oídos, pulmones, intestinos, vesícula biliar, vagina, cavidades nasales (70-75\%), y de forma menos frecuente, la cavidad oral, cerebral y traqueopulmonar $(1,6)$. De las anteriormente mencionadas describiremos la presentación de un caso de Miasis cerebral.

\section{Miasis Cerebral}

En el último registro acerca de miasis realizado por Clinical Microbiology Review se describe a la miasis cerebral como excepcionalmente rara, con nueve casos confirmados y dos casos adicionales con sospechas clínicas y radiológicas, de las cuales la evolución suele ser fatal, con dos casos supervivientes (1).

Las especies identificadas fueron: Hypoderma bovisin; Phaenicia sericata, Hypoderma lineatum, Hypoderma spp., y Dermatobia homini. Referente a la ubicación de la infestación, esta parece tener una predilección por los lóbulos frontales, como se observa en siete de los nueve casos (1). Puesto que el lóbulo 
frontal es el más grande y comúnmente involucrado en lesiones cerebrales traumáticas, es estadísticamente más probable que se vea afectado por cualquier proceso en general (3).

El primer caso de miasis cerebral humana fue descrito por Froomin y Kaznelson en 1939 (3), desde entonces, sólo algunos casos han sido reportados en la literatura mundial hasta la fecha, y la mayoría de los informes de miasis en la literatura se originan en países en vía de desarrollo o se han detectado en países industrializados a partir de personas provenientes de regiones tropicales y subtropicales (3). Dentro de los mismos se encuentra el reporte del caso de un inmigrante Colombiano quien dentro de sus antecedentes tuvo una fractura frontal del cráneo y miasis foruncular posterior en la herida(10), con historia de 2 años de cefaleas no específicas y dificultades de aprendizaje, el examen neurológico completo fue normal, al igual que los exámenes paraclínicos, razón por la cual se realizó una RMN cerebral en la cual se evidenciaron múltiples lesiones cerebrales con alta sospecha diagnóstica de miasis cerebral sin confirmación de la misma, ante la no autorización de intervenciones quirúrgicas por parte de la familia.

Ahora bien, se calcula que en América Latina existe un subregistro de los casos de miasis en comparación con los que epidemiológicamente debería padecer la población, teniendo en cuenta los riesgos que implican la localización geográfica y el hábitat de estos insectos en estas regiones (3).

Es por esto que surge la necesidad de reportar en la literatura la presentación de un caso de Miasis y más específicamente siendo la afectación del mismo a nivel cerebral.

\section{Presentación de Caso Clínico}

Día 0, Paciente de 45 años de edad en abandono social, habitante de la calle y consumidor de sustancias psicoactivas, con antecedentes médicos desconocidos relacionados con otras patologías, con múltiples consultas al servicio de urgencias por cuadros de cefalea y malestar general, encontrando al examen físico la presencia de lesiones en el cuero cabelludo, región parietal y occipital consistente en ulceración excavada inicialmente de $15 \mathrm{~cm}$ mal oliente con infestación por larvas y huevos, con pérdida de tejido del cuero cabelludo (ver imagen 1), recibiendo manejo inicialmente con antibióticos, antiparasitarios, curaciones de herida, desbridamientos de zonas necróticas, extracción manual de larvas, proponiéndose también intervención quirúrgica reconstructiva con colgajos e injertos de piel, sin embargo no se lograba finalizar, puesto que en la mayoría de ocasiones el paciente en su grado de abstinencia por consumo de sustancias psicoactivas, solicitaba retiros voluntarios o fugas del hospital teniendo estancias hospitalarias no mayores a 48 horas.

75 días después el paciente ingresa con sobreinfección de cuero cabelludo, con defecto de cobertura, calota expuesta en región parieto-occipital aumentando su tamaño a $20 \mathrm{~cm}$ de diámetro en 19 días, con perforación ósea redondeada en región parieto-occipital con compromiso de ambas regiones parietales, con presencia de bolsillo a nivel occipital, en malas condiciones generales, caquéctico, estado de malnutrición crónica, compromiso neurológico dado por estado de estupor, mirada con desviación forzada a la derecha y pupilas con isocoria hiporeactiva $5 \mathrm{~mm}$ bilateral, movilizando hemicuerpo derecho espontáneamente y hemiplejia izquierda.

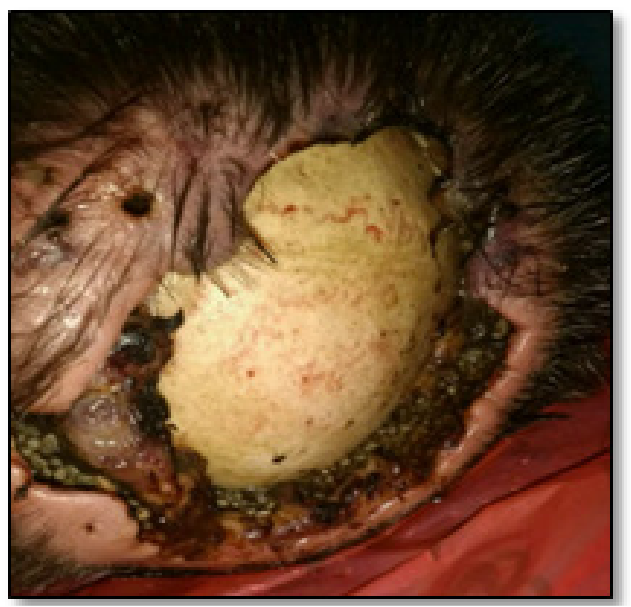

Imagen I. Lesiones en el cuero cabelludo, región occipital consistente en ulceración excavada inicialmente de $15 \mathrm{~cm}$ mal oliente con infestación por larvas y huevos, con pérdida de tejido del cuero cabelludo.

Se solicita primera tomografía computarizada de cráneo simple (ver imagen 2), donde se evidencia ventriculomegalia asimétrica acompañada de zonas de leucomalacia, sistema ventricular y cisternal localizado en la línea media, lesión hipodensa en región fronto-parietal derecho, con pequeño neumoencéfalo frontal derecho contiguo a lesión hipodensa descrita, edema vasogénico frontoparietal severo con borramiento de cisuras en hemisferio derecho, además de ello tabla ósea en región parietooccipital derecha con erosión de los bordes e irregularidad en la continuidad, sospechando de absceso cerebral frontoparietal fase cerebritis por probable miasis intracerebral.

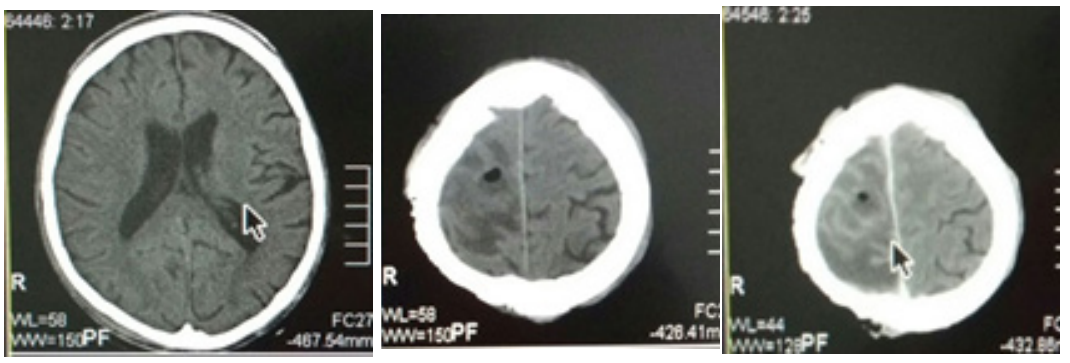

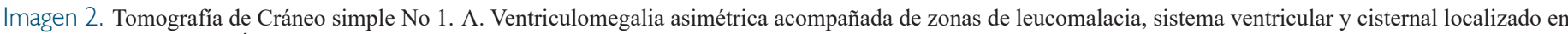

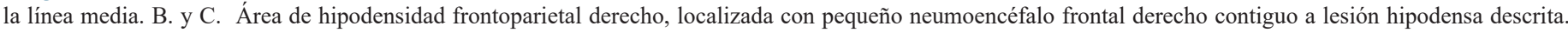
Espacios subaracnoideos con discreta disminución de su amplitud por edema cerebral difuso. 
78 días después del ingreso inicial, paciente con compromiso neurológico por glasgow 10/15, no obedece órdenes, movilizando espontáneamente hemicuerpo derecho, al dolor no retira ninguna extremidad, siguiendo con la mirada al examinador, espontáneamente, gesticulación de sonidos guturales y emaciado, en el día 79 se solicita tomografía de cráneo con contraste (ver imagen 3), en la que se aprecia área de hipodensidad en región fronto-parietal derecha sugestivo de edema con presencia de neumoencéfalo, un área mixta localizada sobre la región fronto-parietal derecha con área circunscrita y captación irregular del medio de contraste con neumoencéfalo, sugestivo de proceso in- feccioso (absceso) y disminución de la amplitud de los espacios subaracnoideos, en el día 81 el paciente se encontraba somnoliento, nistagmus horizontal, desviación lateral de la mirada a la derecha, pulsos débiles, con desviación de la comisura labial a la izquierda, sialorreico, fuerza muscular $0 / 5$ en hemicuerpo izquierdo, reflejos de miembros inferiores en estado de clonus $(+++/++++)$, presentando episodios de crisis discognitivas, epilepsia focal sintomática. Se considera paciente cursando con absceso cerebral frontoparietal, fase cerebritis, muy probable miasis intracerebral, por miasis cutánea y en calota.

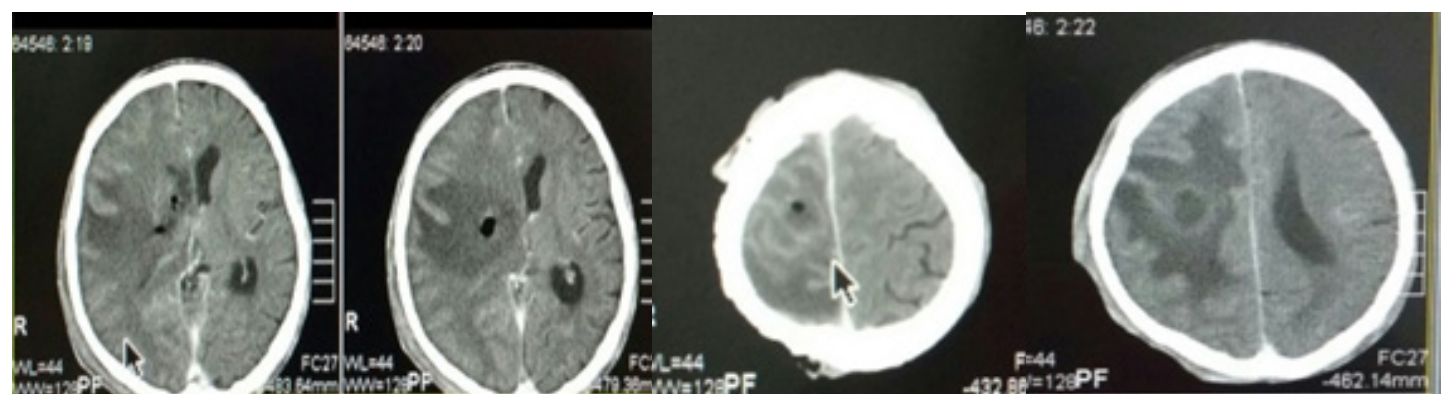

Imagen 3. Tomografía de Cráneo con contraste No 2. A, B y C Área de hipodensidad en región fronto-parietal derecha sugestivo de edema con presencia de neumoencefalo, D. Área mixta localizada sobre la región fronto-parietal derecha con área circunscrita y captación irregular del medio de contraste con neumoencefalo, sugestivo de proceso infeccioso (absceso) y disminución de la amplitud de los espacios subaracnoideos.

Teniendo alta probabilidad etiológica por miasis, se consideró paciente con probable absceso, con defecto en tabla ósea, riesgo de crisis focales complejas no convulsivas razones anteriores por las cuales durante las cortas hospitalizaciones se realizaron curaciones de la herida, y desbridamiento de zonas necróticas solicitadas por cirugía plástica, así como también extracción manual de larvas y huevos (ver imagen 4), se utilizaron medicamentos tópicos como apósitos biológicos de Gentamicina, Nitrofurazona o Terramicina, antibiótico terapia endovenosa en diferentes ciclos durante sus ingresos con Oxacilina 2 gr cada 4 horas, Clindamicina $600 \mathrm{mg}$ cada 6 horas, Meropenem 1 gr cada 8 horas, gentamicina $80 \mathrm{mg}$ cada 12 horas, Metronidazol $500 \mathrm{mg}$ cada 8 horas y en última instancia Ciprofloxacino $500 \mathrm{mg}$ cada 12 horas, Dicloxacilina 500mg via oral cada 6 horas, antiparasitario con Ivermectina 60 gotas vía oral dosis única y 10 gotas en lesiones y otros medicamentos que fueron ordenados por los servicios de psiquiatría para el manejo de la abstinencia, Haloperidol ampolla $5 \mathrm{mg}$ im cada 12 horas, Clozapina $25 \mathrm{mg}$ cada 12 horas, Pipotiazina $50 \mathrm{mg}$ im dosis unica, Levomepromazina 7- 7-15, por parte del servicio de medicina interna utilizaron medicamentos tales como Eritropoyetina 4000 UI semanales, Ácido fólico $1 \mathrm{mg}$ vía oral cada día, sulfato ferroso $200 \mathrm{mg}$ vía oral cada día para el manejo de la desnutrición crónica principalmente, además de ello se utilizó Ácido valproico 250mg vía oral cada 12 horas y Levetiracetam $500 \mathrm{mg}$ cada 12 horas vía oral para manejo de episodios de crisis convulsivas. Así como también resaltamos que durante las diferentes consultas e intentos de hospitalización se tomaron paraclínicos donde principalmente se encuentran pruebas de función renal sin alteraciones, hemogramas con anemia normocitica (Hemoglobina: $7.0 \mathrm{~g} / \mathrm{dL}$, Hematocrito: $24.5 \%$, MCV: $84.8 \mathrm{um} 3$ ), trombocitosis (720x105/ $\mathrm{mm} 3$ ) esta última posiblemente asociado al proceso infeccioso del cuero cabelludo que cursaba el paciente, y en última hospita- lización leve leucocitosis y neutrofília (Leucocitosis 12.8 x 103/ mm3 Neutrófilos 84.4\%), no se encuentran otras alteraciones, durante estancias hospitalarias.

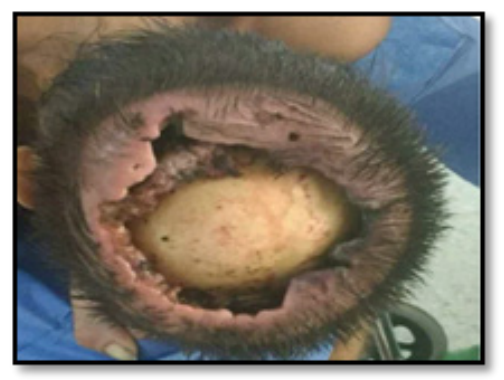

Imagen No. 4. Lesiones en el cuero cabelludo, región occipital en ulceración excavada de $20 \mathrm{~cm}$ posterior a extracción manual de larvas y huevos.

De igual manera se propone al servicio de neurocirugía realizar biopsia de tejido neurológico comprometido, sin embargo, consideran que, dado el estado nutricional del paciente, y debido a las limitaciones por la no disponibilidad de insumos en nuestra institución pública, no era posible realizar prioritariamente la intervención, por lo que se considera que este retraso incrementó el deterioro en el paciente disminuyendo la probabilidad de mayor recuperación.

Pasados 85 días de su ingreso inicial el paciente no realiza contacto visual con examinador, mirada fija al frente, no emite lenguaje; posterior a tratamiento de desbridamiento por el servicio de cirugía plástica, tratamiento antibiótico endovenoso ya descrito y control de crisis convulsivas con antiepilépticos, el paciente fallece en hospitalización. 
DÍA 0 Lesiones en cuero cabelludo en región occipital: ulceración de $15 \mathrm{cms}$, mal oliente, infestación por miasis: múltiples consultas, retiros voluntario no finaliza tratamiento, paciente de mal aspecto, descuidado

1.Miasis en cuero ca- - Ivermectina repetir en 36 belludo

horas

DÍA 0

2. Celulitis de cuero cabelludo

- Curaciones y desbrida- LUNTARIO miento de zonas necróticas - oxacilina 2 gr iv cada 4 horas en $100 \mathrm{cc}$

- clindamicina $600 \mathrm{mg}$ iv cada 6 horas en $100 \mathrm{cc}$ de ssn - ivermectina dar 45 gotas via oral hoy / repetir en 5 dias

DÍA 6 Deterioro de estado general lesión ulcerativa escavada de $15 \mathrm{~cm}$ de diámetro región parietal bordes irregulares con pérdida de tejido de cuero cabelludo, zonas de tejido necrótico, miasis, larvas y huevos, olor fétido, exposición de calota.

1. Miasis Cutánea

2. Abandono Social

3. Antecedente

Valoración por cirugía plástica: curación con fitoestimuline diariamente, mantener cerrada la herida.

Valoración Por Nutrición: Desnutrición Grado II

DÍA 10 Cabeza con defecto de cobertura y exposición ósea a nivel de parietal derecho, con ulcera de aproximadamente $15 \mathrm{~cm}$,

Con zonas de tejido necrótico, con presencia de miasis larvas y huevos, olor fétido.

- Valoración por cirugía plástica curaciones diarias igual manejo antibiótico

- Valoración por psiquiatría: ácido valpròico tabletas $250 \mathrm{mg}$ vo $1-0-1.2$. Levomepromazina gotas 10-10-20.

- Valoración por medicina interna: continuar antibióticos cierra interconsulta manejo por plástica

DÍA 31 Remitido del hospital del sur: cefalea, malestar general

Valoración por psiquiatría clozapina $25 \mathrm{mg} 1$ - 0 - 1. 2. Se cierra interconsulta.

Medicina interna se cierra ic se sugiere tto antibiótico y antiparasitario
Consumo

De Spa

-Meropenem 1 gr iv cada 8 RETIRO VOhoras día 0 LUNTARIO -Clindamicina $600 \mathrm{mg}$ iv POR ABSTIcada 8 horas dia 0

NENCIA AL

De -Ivermectina 45 gotas via CONSUMO oral dosis única DÍA 8

Curaciones de herida

4. Desnutrición Proteico calórica Severa

1.Miasis cutánea de - Meropenem 1 gr iv cada 8 cuero cabelludo re- horas gión parietal derecha

- Clindamicina $600 \mathrm{mg}$ iv

RETIRO VOcada 8 horas

2. Síndrome de absti- - Ivermectina 45 gotas vía nencia oral dosis unica.

- Midazolm 10 mg im dosis única.

- Oxacilina 2amp iv cada 6 horas

RETIRO VO-

- Clinidamicina 1 amp iv cada 8 horas LUNTARIO

- Ivermetina 60 gotas vo ahora repetir en 15 dias aplicar zona afectada 10 gotas ahora 
DÍA 50 Remitido del sur por anemia y herida en cuero cabelludo con sobreinfección, Calota expuesta en región occipital de $20 \times 20 \mathrm{~cm}$ aproximadamente.

Defecto de cobertura- exposición de calota a nivel coronal, con bordes eritematosos

30/03/2017 ivermectina 60 gotas una dosis por 3 días

DÍA 64 Remitido del hospital del sur, cefalea intensa Exposición de calota en área occipital, con avulsión parcial de región frontoparietal con abundantes larvas en bolsillo formado por avulsión.

Plástica: curaciones diaria con terramicina o furasin gentamicina $80 \mathrm{mg} / 2 \mathrm{ml}$ solucion inyectable $1 \mathrm{amp}$ ev cada 12 horas

Psiquiatria pipotiazina $25 \mathrm{mg}$, aplicar $2 \mathrm{amp}$ im dosis unica. Levomepromazina gotas. 7-7-1

DÍA 77 Remitido del hospital del sur por hemiplejia izquierda, Ulcera de aproximadamente $20 \mathrm{~cm}$, en región de galea aponeurita. Comprometiendo ambas regiones parietales bolsillo a nivel occipital

Hemiparesia izquierda no rigidez nucal somnoliento IDx: Encefalitis por infección hematógena por miasis, vs tumor cerebral vs hemorragia vs absceso cerebral

Firma retiro voluntario se arrepiente 26/04/2017 Agitación psicomotora, cae de la cama con contusión, hematoma y palpación irregular osea.

Valoración por neurología malas condiciones generales, caquectico estado de malnutrición crónica. Estuporoso, mirada con desviación forzada a la derecha no cruza línea media, hiporeactiva $5 \mathrm{~mm}$ bilateral, moviliza hemicuerpo derecho espontáneamente, Hemiplejia izquierda.

Manejo por neurocirugía por el compromiso de la lesión para drenaje del tejido y corrección del defecto óseo del paciente con complicación actual de neumoencefalo.

27/04/2017: Perdida de cuero cabelludo en región superior de región parieto occipital extensa,con exposición de calota.
1.Miasis cutánea,

2. Celulitis,

3. Sx anémico a estu-

dio,

\section{4.}

4. Ap consumo de spa,

- Haloperidol amp 5 mg im cada 12 horas

- Ácido fólico amp $1 \mathrm{mg}$ vo cada día

5. Desnutrición

- Sulfato ferroso tab $200 \mathrm{mg}$

vo cada dia

- Oxacilina amp 1 gr 2 amp

iv cada 4 horas

- Clindamicina amp $600 \mathrm{mg}$

iv cada 6 horas

- Ivermectina 60 gotas vo cada día por 3 días

- Dicloxacilina tab $500 \mathrm{mg}$

1. Miasis cutánea a dar 1 tab vo cada 6 horas

nivel occipito-parietal - Furacin + extracción de lar-

bilateral.

vas manual

- Curaciones diaria con te-

2- Farmacodependen-

cia.

rramicina o furasin --gentamicina $80 \mathrm{mg} 1 \mathrm{amp}$ ev cada 12 horas

3- Desnutrición pro- - Pipotiazina $25 \mathrm{mg}$, aplicar 2 teico-calórica.

amp im dosis única.

-levomepromazina gotas.

7-7-15

- gentamicina 2 amp dia

Curaciones diaria con fura$\sin$

$26 / 04 / 2017$

- metronidazol 500mg iv FALLECE cada 8 horas

-clindamicina $600 \mathrm{mg}$ iv cada 6 horas

-acido valproico $250 \mathrm{mg}$ vo cada 12 horas (suspensión)

Valoración por neurocirugía

28/04/2017 cambio antibiotico ciprofloxacin

$500 \mathrm{mg}$ cada 12 horas, fi $28 /$ $\mathrm{abr} / 2017$.
DÍA 85

\section{RETIRO VO-} LUNTARIO

DÍA 65 
Se desconoce tiempo de evolución. Membranas fibrinopurulentas en cráneo y piel de bordes.

Gcs 10/15. Alerta, no obedece órdenes, informa enfermería que moviliza espontáneamente hemicuerpo derecho, $\mathrm{Al}$ dolor no retira con ninguna extremidad. Sigue con la mirada al examinador, espontáneamente gesticula sonidos inintelegibles. Emaciado. No ulceras en piel de otras partes del cuerpo.

27/04/2017: Perdida de cuero cabelludo en región superior de región parieto occipital extensa, con exposición de calota.

28/04/2017: Paciente somnoliento, responde al llamado, nistagmus horizontal, desviación lateral de la mirada pulsos débiles se evidencia desviación de comisura labial izquierda, sialorreico, disminución de la fuerza muscular en hemicuerpo izquierdo $0 / 5$, reflejo rotuliano izquierdo $+++/++++$, miembro superior izquierdo con evidente edema en mano, no es posible valorar el examen mental del paciente; Herida cruenta limpia sin miasis sin necrosis, tejido de granulación.

29/04/2017 absceso cerebral frontoparietal fase cerebritis, probable miasis intracerebral2. Miasis cutánea y en calota en resolución

01/05/2017 episodios de crisis discognitivas inicio levetiracetam $500 \mathrm{mg}$ cada 12 horas vo Dx. epilepsia focal sintomática

03/05/2017 apertura ocular espontánea, no realiza contacto visual con examinador, desviación de mirada fija al frente, no emite lenguaje,

No comprende ordenes sencillas, hemiparesia izquierda. No signos de meníngismo. Igual manejo.

\section{Discusión}

Dentro de los principales tipos de clasificación de la miasis, se denota según su localización la Miasis cavitaria, en la cual el ataque de larvas tiene lugar preferentemente, en la extremidad cefálica (senos paranasales (12) y conducto auditivo externo). En donde a la perforación de los huesos del cráneo puede continuar con la invasión del tejido meníngeo y encefálico (3), como se describe en el presente caso; La miasis cerebral se describe como una patología excepcionalmente rara (1), la mayoría de los informes de miasis se originan en países en vía de desarrollo (3), y en Colombia no se ha encontrado reportes oficiales en la literatura (11).

Frente a la invasión cerebral, en la literatura se ha descrito una mayor predilección por la afectación de los lóbulos frontales
(13), puesto que estos son de mayor tamaño y comúnmente involucrado en lesiones cerebrales traumáticas (3). Se conoce un reporte de caso de un paciente con Miasis cerebral asociada a la colocación de un colgajo de craneoplastia (9), y un caso de miasis cerebral postraumática en un paciente VIH $(+)$ y habitante de calle $(2,3,7)$, razón por la cual traemos dichos casos a correlación.

Teniendo en cuenta los mismos, los principales factores de riesgo para la presentación de esta patología son: La exposición de úlceras, infecciones bacterianas de heridas(3), ingesta de alimentos contaminados, el hábito de dormir a la intemperie (indigencia), carencia de condiciones higiénicas adecuadas $(3,4,6)$, factores de riesgo que en su gran mayoría eran presentados por el paciente del caso descrito. 
El diagnóstico definitivo se hace al visualizar e identificar la larva macroscópicamente a través de su morfología (3). Para el presente caso fue evidente la alta probabilidad diagnóstica frente al compromiso con el que cursaba el paciente, sin embargo, la confirmación del género no fue posible frente a las limitantes propias de técnicas de laboratorio en la institución hospitalaria. En cuanto al tratamiento de la miasis, este consiste principalmente en la remoción de las larvas, requiriendo la extracción manual de la aplicación de sustancias tópicas que induzcan la salida de las larvas desde los tejidos y cavidades (11). Tal como se realizó al paciente del presente caso durante los diferentes ingresos hospitalarios, Sin embargo la mayor limitante para el manejo en este paciente fueron los múltiples retiros voluntarios posterior al inicio de diferentes tratamientos, por su desafortunado estado de abstinencia, a las diferente sustancias psicoactivas, además de ello por ser habitante de la calle su condición clínica se veía mayormente comprometida, motivo por el cual los esquemas antibióticos y antiparasitarios en el tratamiento de dicha patología no se lograban completar, repercutiendo en el mal pronóstico y evolución de la misma, evidenciado en el fallecimiento del paciente, esto soportado en reportes de la literatura en donde se describe que la mortalidad de las miasis es menor a $10 \%$, sin embargo generalmente asociándose a lesiones cerebrales (3).

Se propone por parte de equipos de salud y trabajando en conjunto con entidades del estado planear actividades de promoción y prevención de estas patologías en las calles, para así brindar un manejo según el caso a nivel intrahospitalario precoz, es complejo adecuar un tratamiento acorde si el paciente ante su estado de compromiso por consumo de sustancias psicoactivas no se torna colaborador para su adecuado tratamiento y evolución satisfactoria, gracias a fugas y retiros voluntarios de los centros de salud, como en el caso del paciente reportado, sin embargo se debe plantear una ley considerando que estos pacientes se encuentran bajo los efecto de las sustancias psicoactivas no se debe tener en cuenta las decisiones que estos tomen sobre sí mismos, se consideraría que bajo estos efectos no son $100 \%$ conscientes de las decisiones que tomen, esto siempre y cuando estas decisiones repercuten o desfavorecen su tratamiento, para así poder en conjunto manejar alteraciones secundarios a las sustancias psicoactivas y de esta manera obtener un buen resultado del tratamiento de este tipo de patologías como la miasis, de igual manera se verán disminuidos los casos en las calles evitando también el desenlace fatal de estos paciente.

El presente caso coincide con los apartados citados, referente a los factores de riesgo, la localización de las lesiones, diagnóstico y medidas terapéuticas, es importante resaltar que en Colombia no se encontraron casos que reporten en la literatura la presentación de miasis cerebral, sin embargo, no queriendo expresar que no se presente, por lo que sugiere la existencia de subregistros y motiva a la realización de estudios e investigaciones referentes a esta patología.

\section{Conclusiones}

La miasis cerebral es una enfermedad extremadamente rara, con pocos registros en la literatura mundial referentes al mismo, sin embargo, no por esto una patología de fácil abordaje puesto que en muchos casos el acceso a los servicios de salud o factores inherentes de cada paciente, modifican el curso propio de la patología. La presentación de esta patología predomina en personas con antecedentes de fractura de cráneo y miasis cutánea.

El diagnóstico oportuno de este tipo de patologías en urgencias se ve limitado por múltiples factores, principalmente por efectos secundarios al consumo de sustancias psicoactivas y ser habitante de calle, lo que además en este paciente limito el uso oportuno de estudios como la tomografía computarizada de cráneo simple lo que probablemente habría evidenciado un compromiso inflamatorio mucho antes que el paciente ingrese a urgencias finalmente con un gran compromiso neurológico.

Es de gran importancia tener en cuenta y evaluar en este tipo de pacientes factores de riesgo para la presentación de miasis cerebral, principalmente la condición de habitante de calle y mala higiene, frente a estas mismas cabe mencionar que pese a que las múltiples estrategias establecidas en los últimos años por el estado colombiano para mejorar la calidad de vida de los habitantes de la calle y erradicar dicha condición, los esfuerzos de los gobiernos locales por la resocialización de esta población han sido infructuosos ya que no han logrado mitigar este fenómeno social. La prevención de la habitabilidad en la calle implica llegar directamente al lugar donde se encuentran estas personas en riesgo, lo importante es que existan políticas públicas que puedan tener aplicación directa para esta población, sumado a esto las problemáticas con el consumo de estupefacientes, en ocasiones para los mismos paciente presenta un obstáculo frente a la resocialización e incluso para recibir un tratamiento médico como se vio reflejado en el caso presentado.

Las limitaciones no son solo inherentes al entorno psicosocial del paciente sino también a las limitantes en nuestra institución teniendo en cuenta el precario sistema de salud con respecto a la pronta oportunidad de los insumos para la intervención neuroquirúrgica, que limitó la corroboración del diagnóstico con la confirmación de la presencia de la larva y su género.

Por último, mencionar que como en la mayoría de las patologías, la prevención juega un papel muy importante, sin embargo, lo que se evidencia es el ingreso de pacientes al servicio de urgencias con grandes compromisos, por esto un diagnóstico y tratamiento oportuno, pueden llegar a modificar el pronóstico de la miasis cerebral.

\section{Conflicto de intereses}

Los autores manifiestan no tener conflicto de intereses en este estudio.

\section{Referencias}

1. Francesconia. Fabio, Lupi Omar. Myiasis, Clinical Microbiology Reviews, 2012; $25: 79-105$

2. Allevato Miguel, Miasis. Act Terap Dermatol 2005; 28: 272

3. Piña-Tornés AA, Salvador-Fernández CL, Lindao-Camacho R, González Longoria-Boada LB, Vintimilla-Burgos NP, Selles M. Miasis cutánea masiva que simula invasión cerebral. Presentación de caso y revisión de la literatura. MÉD.UIS. 2016;29(2):145-53. 
4. Cruz Ceballos Filemón, Miasis, Universidad Nacional Autónoma De México Facultad De Medicina Veterinaria Y Zootecnia - Clínica De Los Bovinos I, Disponible en: http://www.ammveb.net/clinica/miasis.pdf

5. Mengarelli RH, Cevallos MV. Manejo de las miasis en heridas agudas y crónicas: Presentación de casos y revisión de la bibliografía. Rev. argent. dermatol. [Internet]. 2012 Sep [citado 2017 Jul 31]; 93( 3). Disponible en: http://www.scielo.org.ar/scielo.php?script=sci_arttext\&pi$\mathrm{d}=\mathrm{S} 1851-300 \mathrm{X} 2012000300004 \& \operatorname{lng}=$ es.

6. Arenas-Rojas AM, Barajas-Ramírez NA. Miasis oral en un paciente adolescente con déficit neurológico crónico. MÉD UIS. 2015;28(3):381-5.

7. Terterov Sergei, Taghva Alexander, MacDougall Mattew, Giannotta Steven, Posttraumatic Human Cerebral Myiasis, World Neurosurgery, 2010;73 (5):557-559.

8. Duque S. Francisco L., Rafael Valderrama H., Jorge Gonzalez R. TRratamiento de miasis oral con ivermectina. Notificacion de tres casos causados por Cochliomia hominivorax (Coquerel). Rev Fac Odont Univ Ant, 1998; 10 (1): 41-47.
9. Giri SA, Kotecha N, Giri D, Nayak N, Sharma A, Cerebral Myiasis associated with artificial cranioplasty flap: A Case Report, World Neurosurgery, 2015: 1-9

10. Marco de Lucas, E. Dìez Consuelo, Gutièrrez F. Montiaga Arnàiz.J, Mandly Andrès Gonzalez, Sànchez. E, Valle N; Case report Unusual MRI indings in a patient with history of frontal fracture and skin infestation by fly laarvae as a posible sign of intracerebral myiasis; Clinical Neurolology and Neosurery 2008; 110 (8): 725 - 728.

11. González C., Salamanca J.C., Olano V., Pérez C. Miasis Cavitaria. Reporte De Un Caso. rev. fac. med. 2008; 16 (1): 95-98.

12. Taha A. Jana, Navid Redjalb, Brian P. Walcottb, Sameer A. Sheth. Intranasal myiasis: A rare complication of transnasal skull base surgery. Case Reports/Journal of Clinical Neuroscience 2013; (20): 1178-1180.

13. Cheshier SH; Bababeygy SR; Higgins D; Parsonnet J; Huhn SL, Cerebral myiasis associated with angiosarcoma of the scalp: case report. Neurosurgery. 2007; 61(1): E167 